\title{
LE ROMAN
}

\author{
DE \\ R E N A R T \\ PUBLIÉ \\ PAR \\ ERNEST MARTIN
}

PREMIER VOLUME

PREMIÈRE PARTIE DU TEXTE:

L'ANCIENNE COLLECTION DES BRANCHES

STRASBOURG

K. J. T R U B N E R, E D I T E U R

PAKIS

ERNEST LEROUX

1882 
nomencm

Imprimerie de G. Otto \& Darmstadt. 